\title{
Care of the dying as a paradigm for true healthcare
}

\author{
E Ireland \\ General Medical Practioner, Kintyre Medical Group, Muasdale, Argyll
}

KEYWORDS care, dying, end of life care

DECLARATION OF INTERESTS No conflict of interests declared.

\author{
Correspondence to $E$ Ireland \\ Kintyre Medical Group \\ Muasdale Surgery \\ Muasdale \\ Argyll PA29 6XD
}

e-mail elizabeth.ireland@nhs.net
At some time in their careers, all doctors will care for patients who are dying. People in the last year of life access services through health and social care more often, and more frequently, than at any other time of life. Recent Scottish studies confirm that $30 \%$ of people in a hospital bed are in the last year of life' and that $9 \%$ of people in hospital will die during the current period of admission. An even more striking statistic indicates that $50 \%$ of all hospital complaints relate to end of life care. ${ }^{2}$

People who are dying have a range of physical, emotional, psychological and social needs. The care system which supports them is complex, and currently under intense pressure. People at the end of life may require health and social care co-ordinated across primary care, out-ofhours services, the ambulance and patient care services, acute and community hospitals, care homes and other local authority and voluntary sector services. Communication is of paramount importance and frequently breaks down. Performance frameworks and governance constructs, while necessary and useful, can be construed as cutting across good care. A patient's trust in the end of life care provided for them or their loved ones can be eroded precipitously, as was seen during the recent demise of the Liverpool Care of the Dying Pathway (LCP).

How then can care of the dying be seen as a paradigm of true healthcare?

Time and time again people tell us it is the humanity of the staff they come across that makes the difference to their experience.

I am trying to raise awareness, understanding and empower people to help prevent families reaching crisis situations. All too often on our journey we were lost, lonely, isolated but looking back my heart can sometimes smile and this is in thanks to the kindness of special people we dealt with.
Like the District Nurse who put her arm around me one day when I was in tears and said 'You're doing ok Tom you're doing ok'. I can't tell you how much I needed someone to do that as I was scared of what was happening and scared of letting my mum down.

It's people who change lives through their help, kindness and understanding and it is important to celebrate this so that others notice and follow.

Over and above policies, strategies and reports it's people who have the potential to transform people's lives throughout what can be a very difficult and lonely journey.

Tommy Whitelaw, 3 September 2014 ${ }^{3}$

The staff in the hospital showed compassion, all of them. They were, of course, professional and I could see evidence of the myriad of forms and processes that are required of them to demonstrate adherence to best practice in cleanliness, safety, nutrition, skin and bowel care etc.

However for Mum and me it was the kindness, the compassion, the small touches that made these last few days an extension of a life lived well and enabled mum to have the death that she wished: one of minimal fuss, minimal intervention and one of immense dignity.

It is the very essence of the humanity of our colleagues that makes the difference to people when it is their turn to be a patient. Everyone saw mum as her, not her disease, her condition, her pain.

A letter of thanks from a doctor on the death of her mother, summer 2014

As a necessary adjunct to our other clinical tools and skills, how can we ensure that this humanity is present 
in the care we provide? Testimonials such as those above, as well as recent well publicised failures in health and social care, should make us pause and reflect on our personal contribution as human beings, as well as clinicians and members of multi-disciplinary and multiagency teams, to the care of people who are dying.

Much has been written, in a variety of quarters, about the LCP. The 2013 independent review of the LCP under the chairmanship of Baroness Julia Neuberger ${ }^{4}$ recognised how the LCP could and did support good care at the end of life, but outlined how the desire for standardisation could allow focus to fall on process and ticking boxes rather than on the need to address complex issues, while at the same time listening, talking and maintaining trust with people and their families.

Caring with compassion for people at the end of their lives should be the aim of all doctors, nurses and healthcare staff. Good care for the dying is as important as good care at any other time of life. ${ }^{4}$

The failure of the LCP may be viewed largely as a failure of humanity - its use should never have been seen as a proxy for thoughtful, individualised end of life care. ${ }^{5}$ The follow up report ${ }^{6}$ outlines key priorities (see Box I) for care at the end of life to be implemented as the LCP is phased out. These priorities are similar to the interim guidance issued by the Scottish Government in December 2013. ${ }^{7}$

Physicians in Scotland are fortunate to work within a system which allows us access to some of the tools which will assist in delivering these priorities. Thanks to a series of recent policy initiatives, ${ }^{8-12}$ we operate within a framework of end of life care which is the result of a lengthy and often intense process of multi-disciplinary collaboration and review ${ }^{13-15}$ aimed at ensuring the consistent and equitable delivery of the highest possible quality of palliative and end of life care for everyone across Scotland who needs it.

This has produced an array of systems, processes and tools which should make that delivery possible. It is our responsibility as individual clinicians, whatever our role, to be aware of and to use these resources. They include measures to identify people who have palliative care needs (SPICT - Support \& Palliative Care Indicators Tool' ${ }^{16}$, to assess, plan and coordinate care to meet those needs, ${ }^{15,17}$ to ensure that families have up to date information (Palliative Care Zone, NHS Inform ${ }^{18}$ ), and to enable staff to collaborate more easily across different care settings (The Palliative Care Direct Enhanced Service for Primary Care (DES) ${ }^{19}$ through the use and access of the Electronic Key Information Summary $\left(\mathrm{eKIS}^{20}\right)$.

\section{BOX I. PRIORITIES FOR CARE OF THE DYING PERSON}

The Priorities for Care are that, when it is thought that a person may die within the next few days or hours:

I. this possibility is recognised and communicated clearly, decisions made and actions taken in accordance with the person's needs and wishes, and these are regularly reviewed and decisions revised accordingly

2. sensitive communication takes place between staff and the dying person, and those identified as important to them

3. the dying person, and those identified as important to them, are involved in decisions about treatment and care to the extent that the dying person wants

4. the needs of families and others identified as important to the dying person are actively explored, respected and met as far as possible

5. an individual plan of care, which includes food and drink, symptom control and psychological, social and spiritual support, is agreed, co-coordinated and delivered.

These latter developments are crucial to the successful delivery of a personalised end of life care plan for every patient. The DES invites general medical practices to share information about people's care provision and preferences by entering data in the eKIS. With permission, this is shared automatically with NHS 24, out-of-hours services, the Scottish Ambulance Service and through a clinical portal in acute care settings.

Increasing numbers of eKIS are in place, allowing information to be shared regarding contact details, preferred place of care, resuscitation status and medication and equipment available in the home. An eKIS can also be printed out for people to have with them in the event of accessing care in a different sector.

We can and must become experts in the use of such tools and systems, but unless we also give our humanity and exercise simple human kindness and compassion in our dealings with our patients and their loved ones, this is not enough. Our responsibilities go further. It is our ability to listen and communicate sensitively with openness and honesty that enables people who are dying, or those close to them, to identify what it is that is important to them. It is this sensitivity that engenders trust - the trust that we can be realistic in agreeing with them what is, and is not, possible. A recent editorial in the JRCPE ${ }^{21}$ addresses these issues eloquently.

In order to ensure patients remain at the centre of all that we do, we as clinicians must ensure we retain our own humanity and care for our own spirituality. Do we as doctors reflect on the impact we have in our 
teams? If we are ill at ease as human beings in talking about death and dying, about recognising and exploring what uncertainty and failure of treatments might mean, then how do we empower those we work with to take the opportunity to have significant conversations with patients and carers when and where the time arises? Are We Living and Dying Well Yet?, a recent report by Marie Curie Cancer Care and the Scottish Partnership for Palliative Care, ${ }^{14}$ observes:

Reliable and consistent provision of good care in the last days and hours of life requires appropriately trained and educated staff, working within environments which support and enable them to use their skills and knowledge. ( $\mathrm{P}$ 10)

As members, and especially as leaders of multidisciplinary teams, we all have a responsibility for creating that environment. Junior members of the team must feel empowered to seek help from appropriate senior clinicians when they need it. If clinical leadership is absent, then culture and practice do not change. Clinical leaders can translate current policy imperatives, lead multi-disciplinary teams, enable clear decision making and empower all staff to deliver the most complex care to those with the greatest needs in a way that is safe, effective, person-centred and compassionate. Clinical leadership is needed to enable our organisations to have the maturity to recognise when care has failed people, to learn from this and to enable staff to take forward different ways of working that aim to improve care, outcomes and experiences for patients.

To make this happen, we should all be working within the parameters of the shared values of the Scottish Government's 2020 workforce vision: ${ }^{22}$

\section{REFERENCES}

I Clark D, Armstrong M, Allan A et al. Imminence of death among hospital inpatients: Prevalent cohort study. Palliat Med 20।4; 28: 474-9.

2 Audit Scotland. Review of Palliative Care Services in Scotland. August 2008. http://www.audit-scotland.gov.uk/docs/health/2008/ nr_08082I_palliative_care.pdf (accessed 4/I I/20 I4).

3 Tommy on tour. http://tommy-on-tour-20II.blogspot.co.uk/ (accessed 4/II/20I4).

4 Neuberger J. More care, less pathway. A review of the Liverpool Care of the Dying Pathway. London: Department of Health; 2013. https:// www.gov.uk/government/uploads/system/uploads/attachment data/file/2 I 2450/Liverpool_Care_Pathway.pdl (accessed 4/I I/20 I4).

5 Scottish Partnership for Palliative Care. Annual Conference. http:// www.palliativecarescotland.org.uk/content/annualconference-20I4/ (accessed 4/II/20I4).

6 Leadership Alliance for the Care of Dying People. One chance to get it right. Improving people's experience of care in the last few days and hours of life. June 2014. https://www.gov.uk/government/uploads/ system/uploads/attachment_data/file/323188/One_chance_to_ get_it_right.pdf (accessed 4/I I/20I4).
- Care and compassion

- Dignity and respect

- Openness, honesty and responsibility

- Quality and teamwork

What does this mean in practice? It means we should:

- demonstrate our values in the way we work

- use our values to guide the decisions we take

- treat each other with respect and dignity across the care system

- have a knowledge and understanding of each other's roles

- identify and deal with behaviours that don't live up to our expectations

- take time to listen, to our colleagues as well as to our patients and those close to them

Above all, it means that we should be responsible, not just for the work we do, but for the way we do it. There is only one chance to get it right when it comes to end of life care. Here more than anywhere we need to cling to our values, and to the humanity and integrity which are at the core of our professionalism. We need to recognise that meeting the needs of our patients, and our colleagues, requires not just knowledge and skill, but teamwork, leadership, and the exercise of our own personal qualities. If we can do this every time, everywhere, for every patient in our care who is dying, then perhaps we may, after all, be justified in claiming end of life care as a paradigm for true healthcare in every context.

\section{Acknowledgment}

Mrs Pat Wallace, retired director of the SPPC, for her support when writing this editorial.
7 NHS Scotland. Interim Guidance: Caring for people in the last days and hours of life. December 2013. http://www.scotland.gov.uk/ Resource/0044/0044I053.pdf (accessed 4/II/20I4).

8 NHS Scotland. Better Health, Better Care: A discussion document. Scottish Executive; 2007. http://www.scotland.gov.uk/resource/ doc/194854/0052337.pdf (accessed 4/I I/20I4).

9 NHS Scotland. Building a health service fit for the future. Scottish Executive; 2005. http://www.scotland.gov.uk/resource/ doc/924/00I2II3.pdf (accessed 4/II/20I4).

10 Scottish Government. Living and Dying Well: a national action plan for palliative and end of life care in Scotland. Scottish Government; 2008. http://www.scotland.gov.uk/resource/doc/239823/0066/55.pdf (accessed 4/II/20I4).

II Scottish Government. The Healthcare Quality Strategy for NHSScotland. May 2010. http://www.scotland.gov.uk/Resource/ Doc/3II667/0098354.pdf (accessed 4/II/20I4)

12 Scottish Government. A Route Map to the 2020Vision for Health and Social Care. May 2013. http://www.scotland.gov.uk/ Resource/0042/00423 I88.pdf (accessed 4/II/20I4). 
13 Scottish Government. Living and Dying Well: Building on Progress. January 20I I. http://www.scotland.gov.uk/Publications/20I I/0I/27090834/0 (accessed 4/II/20I4).

14 Marie Curie Cancer Care/Scottish Partnership for Palliative Care. Are we Living and Dying Well Yet? http://www.palliativecarescotland org.uk/content/publications/Are-We-Living-and-Dying-Well-YetFINAL-REPORT.pdf (accessed 4/I I/20I4).

15 Palliative Care Guidelines. NHS Scotland. http://www. palliativecareguidelines.scot.nhs.uk (accessed 4/II/20I4).

16 NHS Lothian and The University of Edinburgh Primary Palliative Care Research Group. Support \& Palliative Care Indicators Tool. http://www.spict.org.uk/ (accessed 4/I I/20I4).

17 The Scottish Government. Do Not Attempt Cardiopulmonary Resuscitation. http://www.scotland.gov.uk/Topics/Health/QualityImprovement-Performance/Living-Dying-WelI/DNACPR (accessed 4/II/20I4).
18 NHS Inform. Palliative Care Zone. http://www.nhsinform.co.uk/ PalliativeCare (accessed 4/II/20I4).

19 The Scottish Government. The Primary Medical Services Directed Enhanced Services (Scotland) 2012 Palliative Care. http://www.sehd. scot.nhs.uk/pca/PCA20I2(M)06.pdf (accessed 4/II/20I4).

20 NHS 24. What is a Key Information Summary? http://www.nhs24. com/Explained/MylnfoNHS24/WhatisKIS (accessed 4/I I/20I4).

21 Sleeman KE. End-of-life communication: let's talk about death.J $R$ Coll Physicians Edinb 2013; 43: 197-9. http://dx.doi.org//0.4997/ |RCPE.2013.302

22 The Scottish Government. 2020 Workforce Vision. http://www. scotland.gov.uk/topics/health/nhs-workforce/policy/2020-vision (accessed 4/I I/20I4).

\section{VACANCY Education Editor}

The RCPE is looking to recruit an Education Editor who will be responsible for editing the Education section of The Journal of the Royal College of Physicians of Edinburgh, the College's quarterly peerreviewed, open access, general medical journal (international circulation: 8,000). The JRCPE is indexed in Medline and Embase, Google Scholar and the DOAJ.

This position is unremunerated, but reasonable travel expenses will be paid.

Applicants should submit a short CV and details regarding their suitability for the post to:

Graeme McAlister, Head of Fellowship \& Membership Services, RCPE, 9 Queen Street, Edinburgh EH2 IJQ.

E-mail: g.mcalister@rcpe.ac.uk

Interviews are provisionally scheduled to take place w/c 17 February 2015.

\section{Responsibilities will include}

- commissioning and editing Expert Reviews and Rapporteur Reports from the College's symposia programme

- $\quad$ selecting CME material for potential reproduction in the $J R C P E$

- liaising with the editorial team to aid the development and editorial direction of the $J R C P E$, including overseeing the development of new content streams and contributing ideas for future editorials and other content

The Education Editor will work closely with the in-house editorial/production team.

Interested candidates should be a Fellow of the RCPE, have a demonstrable interest in medical education and international developments in general internal medicine, and a knowledge of and interest in editing, and commissioning for, medical or scientific journals.

\section{Closing date: 23 January 2015}

If you would like more information about this role or to discuss this vacancy informally please contact Graeme McAlister on 0I3I 2473693 or by e-mail at the above address. 